\title{
El humorismo tragicómico en dos cuentos de Tinieblas (1923), de Elías Castelnuovo
}

\author{
Tragicomic humour in two stories from Tinieblas (Gloom, 1923), by Elías \\ Castelnuovo
}

\author{
Esteban V.Da Ré \\ estebanvd@gmail.com \\ Universidad de Buenos Aires - Consejo Nacional de \\ Investigaciones Científicas y Técnicas, Argentina
}

Recepción: 10 Febrero 2020

Aprobación: 24 Agosto 2020

Publicación: 06 Noviembre 2020

Cita sugerida: Da Ré, E. (2020). El humorismo tragicómico en dos cuentos de Tinieblas (1923), de Elías Castelnuovo. Orbis Tertius, 25(30), e162. https://doi.org/10.24215/18517811e162

\begin{abstract}
Resumen: La mayor parte de la crítica literaria elabora sus hipótesis sobre la poética de Elías Castelnuovo a partir de la lectura de Tinieblas (1923), su primer libro de cuentos, al tiempo que señala que es el autor más representativo del llamado grupo de Boedo, conjunto de artistas, escritores e intelectuales que se propuso contribuir a la elaboración de una cultura revolucionaria. Los principales desarrollos críticos sobre este libro destacan sus rasgos "naturalistas", "tremendistas", "pietistas" y "mesiánicos" así como una intencionalidad política "ingenua” y "esquemática". No obstante, una relectura de dos de los cuentos de Tinieblas, en consideración del humor tragicómico que su temprana recepción advierte en su obra, permite reconsiderar las conclusiones críticas contemporáneas y elaborar nuevas hipótesis de lectura.
\end{abstract}

Palabras clave: Literatura argentina, Humor, Parodia, Izquierda, Boedo.

\begin{abstract}
Most literary critique develops hypotheses on Elías Castelnuovo's poetics from their reading of Tinieblas (1923), his first book of short stories, pointing him out as the most representative author from the so-called Boedo group: a set of artists, writers and intellectuals who aimed at creating a revolutionary culture in the 1920 s and 1930s. The main critical developments on this book highlight its "naturalistic", "tremendistic", "pietistic" and "messianic" traits, as well as a "naïve" and "schematic" political intent. However, a rereading of two of the stories in Tinieblas, focused on the tragicomic humor that their early reception perceived, allows for a reconsideration of contemporary critical conclusions and the elaboration of new reading hypotheses.
\end{abstract}

Keywords: Argentine Literature, Humor, Parody, Left, Boedo.

\section{Tinieblas, Castelnuovo, Boedo y el Problema de SU Recepción CRítica}

En las distintas lecturas que realiza la crítica del libro Tinieblas (1923), de Elías Castelnuovo, se cifran aspectos claves del ordenamiento y valoración del campo literario durante el proceso de modernización cultural (Sarlo, 1988) que se opera en la Argentina en las primeras décadas del siglo XX. Castelnuovo es considerado el autor cuyas obras ficcionales son las que mejor expresan las características de la literatura 
del grupo de Boedo (Portantiero, 1961; Candiano y Peralta, 2007; Saítta, 2008), conjunto de escritores "que vienen del anarquismo, del socialismo filomarxista, del socialismo que llamaríamos nacional, y de una izquierda fluctuante y sin banderías" (Prieto, 1959, p. 18) y que se propusieron contribuir durante esos años a la conformación de una cultura revolucionaria, bajo el marco abierto por la Revolución Soviética. La cantidad, el alcance y la duración de sus proyectos colectivos, sus opciones políticas y estéticas y las polémicas que establecieron con otras concepciones del arte constituyen al grupo de Boedo en una experiencia fundamental dentro de la cultura argentina. Si bien Tinieblas había tenido su primera edición en 1923, con anterioridad a la conformación del grupo, resulta la obra más analizada de Boedo como consecuencia de que fue reeditada, a fines de 1924, como libro inaugural de la colección "Los Nuevos" de la revista Los Pensadores, una de las principales publicaciones impulsadas por los boedistas. Esta colección de obras literarias de autores "nuevos" tenía como uno de sus objetivos "provocar una reacción entre la juventud que se inicia [en las letras]" (s/p), según se manifiesta en los "Propósitos" publicados en su número 6, del 24 de febrero de 1925. Asimismo, Castelnuovo consigue dos distinciones importantes durante esos años: con anterioridad a la publicación de Tinieblas, un cuento de su autoría obtiene el primer premio en un concurso literario organizado por la revista La montaña -dirigida por José Ingenieros y Leopoldo Lugones- y Tinieblas, al año siguiente de su publicación, es galardonado con el Premio Municipal.

La obra de Castelnuovo, no obstante, fue abordada de manera mayoritaria bajo el estudio del proyecto político-cultural del grupo de Boedo en su conjunto y son excepcionales los trabajos críticos que analizan la producción de Castelnuovo en particular. En estos análisis de su obra se articulan tres tendencias principales que se diferencian, en general, por las características que advierten en las ficciones de Castelnuovo y por la valoración que realizan de su poética. Por un lado, existe una tendencia crítica dominante, dada la cantidad y el alcance de sus trabajos, que formula una explícita y taxativa valoración negativa de su obra, por considerarla "tremendista”, "pedagógica”, de "mal gusto", entre otros atributos. ${ }^{1}$ Asimismo, existe otra tendencia crítica que reivindica el proyecto del grupo de Boedo y de Castelnuovo, percibiendo, en general, los mismos rasgos formales y temáticos que la anterior, pero invirtiendo su signo valorativo. Por último, un conjunto de estudios críticos advierte características de la literatura de Castelnuovo no relevadas por las tendencias señaladas con anterioridad y pondera positivamente otros rasgos de su poética. Asimismo, el tono humorístico de la obra de Castelnuovo o bien no es advertido, o bien se considera un rasgo excepcional que aparece en los primeros años de su escritura literaria y que abandona a partir de Tinieblas.

Respecto de la tendencia crítica dominante, Adolfo Prieto y Juan Carlos Portantiero elaboran en gran medida las primeras hipótesis sobre Castelnuovo y el grupo de Boedo que son retomadas y reformuladas por la mayor parte de los trabajos posteriores. En este sentido, sostiene Prieto:

[...] la literatura de Boedo fracasó, en gran parte, no por ser incapaz de fomentar la rebeldía, sino por creer que la rebeldía puede fomentarse sólo con una literatura piadosa. La importancia atribuida a este elemento, en desmedro de otros, acaso explique la pobreza de registros, la ausencia de densidad, la impresión de superficie que produce mucho de lo escrito por la generación de Boedo (1959, p 20).

Respecto de Castelnuovo en particular, Prieto sostiene que:

[...] desde Tinieblas a Calvario se advierte el desarrollo de una peligrosa parábola: la descripción objetiva (el retrato que impugna por sí mismo) y la piedad con que se describen los destinos humildes, comienzan a transformarse en gusto por el efecto y un vago sentimiento místico-religioso (1959, p. 19).

Por su parte, Portantiero propone una genealogía para la literatura de Boedo y señala que carga con los "vicios teóricos del 900" (1961, p. 115) en tanto no pudo superar "la mala herencia del anarquismo literario" (1961, p. 115) de Evaristo Carriego, Roberto Payró y Florencio Sánchez (1961, p. 115). Respecto de Castelnuovo, sostiene que "nadie como él explicita mejor las características del boedismo como corriente cultural, su aspecto de continuación más o menos lineal de la primera literatura de izquierda" (1961, p. 120) y, en particular, del "populismo, del naturalismo y de la visión piadosa de la clase trabajadora”. Asimismo, 
encuentra que la presencia del "fatidismo mesiánico" (1961, p. 120) propio del anarquismo, mueve "al horror o a la piedad mediante la minuciosa cargazón naturalista de desdichas y tragedias" (1961, p. 120). En un artículo posterior, Adolfo Prieto complementa sus desarrollos previos y afirma:

Boedo se aproximó a la literatura revolucionaria, pero cargaba demasiados lastres como para satisfacer sus propios ideales. Usaron todavía del viejo realismo crítico para denunciar los aspectos sombríos del mundo, y un lirismo tolstoiano para exaltar la virtud de los humildes y de los sumergidos (1964, p. 23).

Dentro del marco valorativo abierto por Prieto y Portantiero, Carlos Giordano señala los "desbordes" (1980 [1968], p. 42) de la poética de Castelnuovo, ligados a su "ingenuo tremendismo" (p. 42):

El gusto por el efecto, el sentimiento de compasión que busca despertar en el lector, con apenas sofrenados escrúpulos, la simplificación de esquemas conceptuales y de las motivaciones que orientan la conducta de sus personajes son, probablemente, los más visibles cargos que puedan efectuarse a las obras escritas por Castelnuovo en los años correspondientes a la experiencia del grupo Boedo (1980 [1968], p. 42).

Así también, Eduardo Romano advierte que Castelnuovo persigue en sus relatos “'asustar' a sus lectores con recursos naturalistas, con descripciones desagradables, con tremendas situaciones irreversibles" que se entraman con "momentos de humildismo tolstoiano" (1981, p. 475). Por su parte, Beatriz Sarlo sostiene que Castelnuovo, en su obra de los años veinte, "se contagia del hipernaturalismo de los manuales médicos y por eso, más que ficciones realistas, escribe 'ficciones científicas' del terror social” (1988, p. 201) por lo que en sus textos "siempre dice lo que un escritor de mejor oficio elude; su voyeurismo es insaciable" (1988, p. 201). Graciela Montaldo profundiza la valoración negativa respecto de las obras literarias de Boedo y afirma que su literatura no debe considerarse como objeto crítico dado que "estéticamente (...) no tiene elementos de interés" (2006 [1989], p. 327) como consecuencia de que "lo estético estaba fatal y legítimamente subordinado a lo ideológico" (p. 327). Completa sus argumentos al sostener que las obras literarias de Boedo "pasaron a ser recortes y ejemplificaciones, muestreos y comprobaciones del funcionamiento que rige la realidad social y política" (p. 325) según un "programa ideológico elevado a categoría de verdad" (p. 325), a causa de que la "función que le asignaron al arte y la literatura fue eminentemente pedagógica" (p. 325). En consonancia con estas afirmaciones, en un artículo posterior, Montaldo (1990) desarrolla con mayor detalle las estrategias pedagógicas de las revistas de Boedo y no aborda el estudio de los textos literarios editados por estas publicaciones. Respecto de las características de estas obras, Alejandro Eujanián y Alberto Giordano encuentran que Boedo realiza una "pedagogización de la literatura, en la que público equivale a pueblo y este a ignorantes que deben ser educados" (2002, p. 407) y, reformulando las conclusiones de Prieto, advierten además que los integrantes del grupo "combinan progresismo ideológico con conservadurismo estético" (p. 406) dado que "apuestan a la función revolucionaria de la literatura a través del respeto ingenuo a los valores de la tradición cultural humanista” (p. 406). Asimismo, Adriana Astutti, también califica a su obra de "vouyerista" (p. 428) y afirma que el realismo de Castelnuovo es "viejo" y "delirante" (p. 428), que su literatura es "involuntariamente caricaturesca" (p. 428) y se "regodea en el detalle escabroso" (p. 433), para concluir que la propuesta de Castelnuovo es una "pedagogía del mal gusto" (p. 436). En esta misma línea, Sylvia Saítta (2008) ofrece una sintética presentación del autor -con el objetivo de analizar sus crónicas de viaje a la URSS- donde condensa las conclusiones de la mayor parte de la crítica literaria sobre su obra cuando afirma que la narrativa de Castelnuovo "fue la que mejor representó las características del grupo de Boedo como corriente cultural al sostener el arte social, el populismo, el naturalismo, la visión piadosa de la clase trabajadora" (2008, p. 100). No obstante, Saítta encuentra que la singularidad de su poética reside en que, a su vez, "excedió (...) los presupuestos de Boedo tanto por su mirada sobre la miseria según una lógica religiosa que difícilmente compartieran sus compañeros de izquierda, como por su fascinación por lo monstruoso, lo miserable, lo horroroso, lo deforme" (p. 100). Por su parte, Marcela Croce -en un trabajo que quizá sea el más reciente sobre este autor- califica a Castelnuovo como un "extremista del morbo" (2017, p. 199), y encuentra que en sus relatos la "alternativa revolucionaria resulta sepultada" (p. 200) por tres características ideológicas: 
el "determinismo físico y no social" (p. 201) del destino de sus personajes, su "profusión evangélica" fatalista y su "pietismo" (p. 201) que se "conmisera con los pobres" (p. 201).

Por otro lado, coexiste otra línea crítica que reconoce las mismas características en el grupo de Boedo y en la poética de Castelnuovo pero que invierte su signo valorativo. En este sentido, Lubrano Zas se distancia de quienes acusan a Castelnuovo de "terrorismo", dado su estilo "sombrío", y vincula este rasgo de su poética con su experiencia de vida, en tanto advierte que, en verdad, esos señalamientos implican un "desconocimiento de la miseria circundante (desocupación, conventillos, etc.) que el autor de Larvas sufrió” (1988, p. 8). Una defensa de la producción de los escritores del grupo de Boedo, con similares argumentos, realiza Raúl Larra en sus libros dedicados a Roberto Arlt (1962) y Leónidas Barletta (1978).

Un tercer grupo de estudios críticos se encuentra conformado por análisis que, si bien no muestran la homogeneidad de las tendencias anteriores, tienen en común el hecho de advertir otras características en la producción de Boedo y de Castelnuovo y de valorar positivamente algunas de sus particularidades. Nicolás Rosa, en un trabajo fundacional al respecto, define a Castelnuovo como "un verdadero artesano de la escritura y un oficiante, pues trabaja sus propios textos como pura manualidad: el oficio de escribir - un verdadero bricouleur de los restos de las Enciclopedias Populares" (1997, p.114). Asimismo, Rosa ubica la poética de Castelnuovo entre las "formas retóricas del miserabilismo" (1997, p. 123) al tiempo que, ideológicamente, percibe un "anarquismo crístico" (p. 123) en el que los relatos no configuran "aventuras" (p. 123) sino "desventuras" (p. 123) de sufrimiento y miseria y se oponen, así a las "formas exhibicionistas de la retórica: el ornato y la exuberancia de los tropos" (p. 123). Por su parte, Martín Prieto, señala que Castelnuovo es “el más obstinado intérprete y difusor del realismo social” (2011 [2006], p. 158) y, en la línea de Montaldo, sostiene que su literatura se encuentra "sometida a un ideal exterior, del que la literatura sería solo su instrumento: la revolución social" (p. 158). Sin embargo, encuentra que esos rasgos se hallan en tensión con la "formidable potencia de su obra narrativa" (p. 158) que se articula en torno de "un naturalismo exasperado" (p. 158) en donde los condicionamientos de la herencia y el medio y "un machacante moralismo ideológico" (p. 158) son "simultáneamente desestabilizados por una desbordada imaginación -sostenida por el discurso de la ciencia experimental-” (p. 158). Leonardo Candiano y Lucas Peralta (2007) toman como objeto de su investigación el análisis del grupo de Boedo y hacen explícita su perspectiva polémica con la tendencia crítica dominante:

Consideramos errado realizar un análisis de Boedo utilizando meramente parámetros ajenos a sus concepciones porque eso sólo sirve para desacreditar su praxis cultural sin explicarnos por qué este grupo de artistas decidió hacer lo que hizo. Ese tipo de análisis juzga, pero no descifra, valora, pero no revela, es cómodo para diatribas, pero no para una comprensión real sobre su práctica específica $(2007$, p. 27).

En relación con Tinieblas, destacan el hecho de estar producido por un "obrero que otorga estéticamente una visión clasista de los asuntos tratados" (2007, p. 206) por lo que se convierte en un texto "fundacional" (p. 206) para Boedo, al condensar los principales objetivos literarios del grupo (p. 206). En relación con los argumentos de los cuentos, sostienen que articulan "imágenes del desconsuelo" (p. 207), al tiempo que la descripción se configura en el recurso privilegiado para "insertar [al lector] en el clima de aflicción” (p. 208) de los relatos. Señalan, a su vez, que estas características "utilitarias y pedagógicas" (p. 211) de las ficciones de Castelnuovo persiguen el fin de "causar un choque, molestar la lectura, motivar una acción, borrar la pasividad del que lee” (p. 209), en consonancia con el proyecto de Boedo de producir una "literatura militante revolucionaria" (p. 209). Asimismo, perciben como procedimientos característicos de su poética las constantes animalizaciones de los personajes, con el objetivo de denunciar los efectos del trabajo inbumano en la sociedad capitalista (p. 213). En relación con el "discurso religioso" (p. 216) en los cuentos de Castelnuovo, señalan -en contraposición con las conclusiones más extendidas- que su aparición recurrente "encierra una sarcástica crítica" (p. 16), en tanto "carga las situaciones narradas de ironía, patetismo y ridículo" (p. 216) y deja en evidencia que la religión sumerge a los personajes en una "pasividad que impide cualquier posibilidad de transformación de sus situaciones reales de existencia” (p. 216). Por otro lado, Miguel Vitagliano (2012) realiza una compilación de artículos críticos respecto del grupo de Boedo que hace foco en sus "políticas 
del realismo". En su artículo, Vitagliano polemiza con la crítica que "da por generalizado" (2012, p. 80) el didactismo de la obra de Castelnuovo y afirma que "sólo encuentra asidero en sus escritos ensayísticos, no en sus textos de ficción” (p. 80). En ese volumen, Oscar Blanco sostiene que la literatura de este grupo es una continuación de la novelística médica positivista argentina, pero que, no obstante, la "critica fuertemente" (p. 16) al señalar que la miseria moral que focalizan los naturalistas argentinos es consecuencia y producto de la miseria material y la pobreza extrema (p. 16) y no de la herencia inmigratoria. Andrés Monteagudo (2012) ofrece en el mismo libro un abordaje original de Castelnuovo cuando vincula sus obras teatrales -y las escenografías de Abraham Vigo de sus puestas en escena- con el expresionismo alemán. Por su parte, Adriana Rodríguez Pérsico produjo una serie de artículos sobre la poética de Castelnuovo (2012, 2013, 2014a, 2014b) a la que nombra como "poética de deshechos" (2013, p. 34), en tanto para el autor "la idea de basura supone un doble movimiento de destrucción y afirmación" (2013, p. 83) que implica "que se pueden imaginar formas a partir de lo inútil, de lo que sobra como resto en la lógica del mercado" (p. 83). Bajo este marco, Rodríguez Pérsico establece vinculaciones entre las ficciones de Castelnuovo y una serie de conceptualizaciones teóricas -la noción de abyección de Kristeva, de heterogeneidad de Bataille, de biopolítica de Foucault, entre otras- que enriquece la mirada sobre la dimensión crítica del capitalismo formulada en la literatura de Castelnuovo. Por su parte, Gabriela García Cedro (2013), si bien centra su análisis en la polémica entre Boedo y Florida desarrollada en revistas culturales, cuestiona la tendencia crítica dominante cuando afirma que Boedo presenta una serie de rasgos que lo ubican, junto con Florida, dentro de las vanguardias porteñas: “experimentación; presencia de la ciudad y las máquinas como epítomes del discurso modernizador; negación (a veces entendida como ruptura) de los modelos anteriores y sus representantes" (2013, p. 376), "discurso autorreflexivo" (p. 377) y "cuestionamiento" (p. 378) a las instituciones.

Dentro de los estudios sobre las ficciones de Castelnuovo son excepcionales los trabajos que perciben la importancia del humor y la parodia dentro de su poética. Francine Masiello es la primera en advertir el tono paródico de Castelnuovo para criticar al naturalismo literario y sus bases presuntamente científicas: "Castelnuovo cuestiona los excesos del naturalismo y sus propuestas de 'verdad' en la ficción. La parodia se usa como instrumento principal para exponer el fraude del proyecto naturalista y reconsiderar la lógica científica que infunde esos textos" (1986, p. 197). No obstante, Masiello limita el alcance de estos cuestionamientos: "Mariani, al igual que Castelnuovo, no llega a escapar del todo a la ideología dominante de la ficción naturalista y sólo juega con resistencias menores para aprobar una rebelión parcial” (1986, p. 200). Por su parte, John E. Eipper centra su análisis en las transformaciones ideológicas de la obra de Castelnuovo que, según afirma, comienza con "raíces anarquistas" (1995, p. 22), de las que se "separa" (p. 24) luego de su viaje a la Unión Soviética en 1931, para aproximarse a una literatura "basada en principios científicos" vinculados con el marxismo (p. 25). Eipper, a su vez, reconoce que su condición de "humorista" (1995, p. 31) y "parodista" (p. 33) es una "faceta olvidada" (p. 31) de Castelnuovo y afirma que este tono humorístico es una excepcionalidad que acontece en el comienzo de su producción, con la publicación de Notas de un literato naturalista (1923): “Cómo y por qué transcurre Castelnuovo, en el breve espacio de dos años, de una visión paródica del naturalismo a libros tan 'patentemente' naturalistas como Tinieblas y Malditos?” (1995, p. 33). ${ }^{2}$ Eipper responde que Castelnuovo considerará más eficaz para sus fines político-literarios presentar en tono serio al hombre sometido por el capitalismo que “ironizar sobre el statu quo mediante la parodia y la sátira” (p. 34). Asimismo, Adriana Rodríguez Pérsico, en uno de los trabajos antes referidos, percibe el tono cómico de Castelnuovo pero encuentra en él una contradicción con su apelación simultánea a procedimientos naturalistas:

Del hipernaturalismo de los manuales médicos, Castelnuovo se burla ya en un texto temprano de 1923, Notas de un literato naturalista. Sin embargo, el gesto es contradictorio puesto que de modo paralelo escribe la serie de narraciones teratológicas que inaugura Tinieblas. El naturalismo de trazos gruesos (o el expresionismo de la prosa) coincide cronológicamente con la parodia de dicha estética (2013, p. 34). 
Este tercer conjunto de desarrollos críticos, aún en su heterogeneidad, muestra como rasgo común la problematización de algunos de los lugares comunes establecidos por la mayor parte de la crítica literaria sobre las ficciones de Castelnuovo - pedagogismo, pietismo religioso, conservadurismo estético- al tiempo que advierte, aunque lo restrinja a un rasgo excepcional, la presencia del humor y la parodia en su poética. En efecto, las publicaciones previas a Tinieblas que Elías Castelnuovo dio a conocer en la prensa anarquista se caracterizan por un humor sarcástico que tiene por objetivo criticar las tendencias principales de la cultura y de la literatura de su tiempo: el discurso católico, la narrativa sentimental, el romanticismo literario, el sainete, el discurso criollista, entre otros. En este sentido, la breve biografía de Castelnuovo que acompaña la publicación de Notas de un literato naturalista, conjunto de relatos que aparecen en 1923 -mismo año de la aparición de Tinieblas - en la colección Las grandes obras, dirigida por Julio R. Barcos, hace énfasis en su humorismo crítico:

Es [Castelnuovo] un actor y espectador dentro de nuestro escenario social; está en el foco de la vida revolucionaria obrera y pasea, al mismo tiempo, el espejo de su espíritu [...] reflejando, a su modo, humorísticamente, pero con un noble y osado humorismo filosófico comparable al de Mark Twain, las costumbres, las ideas y las imbecilidades de nuestros semejantes.

En el fondo de sus burlas llenas de causticidad y de gracia hay, sin embargo, como en el fondo de la risa de Garrik, un timbre patético de tristeza que vela de una noble y exquisita melancolía las mejores páginas de sus cuentos y novelas (Castelnuovo, $1923 \mathrm{a}, \mathrm{s} / \mathrm{n}$ )

De esta manera, la percepción del humor y la parodia en los cuentos “Tinieblas" y "De profundis" para la crítica de la cultura y la sociedad, entramados con episodios trágicos y una sensibilidad expresionista, permite reconsiderar las lecturas dominantes sobre la literatura de Castelnuovo y, en efecto, disolver la contradicción que se le atribuye entre las características de sus ficciones y su proyecto político-cultural revolucionario.

\section{“TiNIEBLAS": SARCASMO E HIPÉRBOLES PARA LA PARODIA DEL NATURALISMO}

“Tinieblas”, el segundo de los relatos del volumen homónimo de Castelnuovo en su primera edición, y el primero a partir de las siguientes, hace foco, en particular, en la parodia del naturalismo, tendencia literaria sobre la que, el mismo año de la publicación de este libro, Castelnuovo ya había también formulado su rechazo burlesco en el cuento "Notas de un literato naturalista"(1923a). En "Notas..." se relata en primera persona la experiencia de un narrador que quiere realizar una novela "naturalista" (1923a, p. 2) sobre una operación que le realizaron a su hermana, "escribiendo seriamente, aplicando el método científico, el examen riguroso, la observación exacta, el microscopio, la radiografía, el teodolito, la teoría de la relatividad” (p. 2). En esta enumeración disparatada de las intenciones de este escritor "naturalista" se advierte, como efecto de lectura, el gesto burlesco sobre la manera en que esta corriente literaria resolvió sus anhelos de cientificidad. En efecto, todo el relato se constituye a partir de una sucesión continua de humoradas respecto del naturalismo literario y la medicina.

El relato "Tinieblas", por su parte, desarrolla un episodio trágico en la vida de su narrador, quien trabaja como linotipista en un "sótano inmenso, húmedo y frío" (1923b, p. 33) donde "se respira el estaño de la muerte” (1923b, p. 33). ${ }^{3}$ En las caracterizaciones del ambiente laboral, el énfasis no está puesto en una descripción externa y objetiva, al modo del naturalismo, sino que se pone en primer plano la percepción subjetiva del narrador respecto de ese entorno y del impacto de los procesos laborales en los trabajadores:

En invierno se nos ponen los pies duros de frío y la nariz roja; en verano sudamos como si estuviésemos hundidos en el infierno de una cámara turca. Arden continuamente los crisoles, crujen las poleas, saltan los tapones y los linotipos no se detienen más que para seguir marchando. [...]

Para rematar el agotamiento que produce esta atmósfera espesa y viciada, las rotativas de vez en cuando, golpean furiosamente el tímpano de los trabajadores. El día que funcionan dos, salgo con un dolor agudo en la nuca que no me permite doblar el cuello con soltura. Siento, además un martillo que me sigue pegando en un punto fijo del cerebro y de noche, en vez de descansar, sueño que compongo -dale que te dale- hasta que me despierto jadeante y fatigado (Castelnuovo, 1923b, pp. 33-34). ${ }^{4}$ 
De esta manera, las descripciones del narrador establecen correspondencias con la caracterización que hace César Aira, para el análisis de la obra de Roberto Arlt, del expresionismo alemán que, según afirma, "funciona por la participación del autor en su materia" (1993, p. 55) y por su "intromisión [...] en el mundo, gesto que no puede suceder sin una cierta violencia” (p. 55). En efecto, según Aira, desde la percepción expresionista

el mundo ha perdido su naturaleza cristalina, se hace gomoso, opaco, de barro. Un mundo de contacto. Y se deforma para hacerle lugar a él, al intruso, se estira, se aplasta, en anamorfosis terroríficas. Obstinado en la inadecuación, el artista se aferra a pesar de todo a los patrones visuales de la representación (no existen otros), y su obra se llena de monstruos (1993, p. 55).

En Tinieblas, esta "deformación" subjetiva del mundo se produce a partir de la mediación de un narrador en primera persona que, a su vez, muestra correspondencias con características biográficas de Castelnuovo: muchas secuencias narrativas de sus cuentos, por ejemplo, reaparecen transformadas en diversas entrevistas al autor en las que cuenta aspectos de su vida y, en particular, en sus Memorias (1974) y se vinculan, así, estas ficciones con experiencias personales. En el caso de este relato, el oficio de linotipista del narrador coincide con una de las múltiples ocupaciones que desarrolló Castelnuovo durante su vida. No obstante, en un giro ficcional y autoparódico, Castelnuovo toma distancia de estos personajes, en tanto que, lejos de presentarse como modelos de conducta, se encuentran atravesados por elementos que llevan a finales desconcertantes, trágicos y burlescos, que difieren de los relatados por Castelnuovo en sus Memorias.

El protagonista de "Tinieblas", si bien muestra similitudes con la figura que presenta de sí mismo Castelnuovo en su autobiografía, se contrapone cuando deposita con resignación esperanzas en Dios, actitud que no aparece en ningún pasaje de las Memorias. Esta resignación le permite al narrador de "Tinieblas" continuar día a día con su trabajo insalubre:

Aunque la alegría de vivir naufragó tempranamente en mi cerebro, creo que Dios no me dejará morir llevando a la tumba esta impresión horrible de la existencia. No, no, yo confío que alguna vez me indemnizará con algo extraordinario de todos los males que he sabido soportar con resignación de piedra durante mi tránsito por el mundo (p. 37).

No obstante, esta "resignación” no recibe ninguna “indemnización” en el relato, pese a las expectativas del protagonista. Camino a su casa en la madrugada, luego de su trabajo, el narrador se encuentra con "una mujer de luto" (p. 38) durmiendo en la calle y, desde su perspectiva, "más que criatura humana parece un envoltorio de basura” (p. 38). José Amícola (2008), al igual que Aira, encuentra en la prosa de Arlt rasgos del expresionismo alemán, en tanto percibe "cierta conjunción inarmónica de colores, luces y movimientos" (p. 161). En este sentido, al igual que la imprenta, un ambiente abierto como la calle también es descripto por el narrador de "Tinieblas" al modo expresionista, en su apelación al contraste entre luces y sombras en movimiento: "Sobre un fondo negro y un escenario frío y resbaladizo, las lámparas eléctricas ejecutaban la danza de la muerte bajo el control musical de los cables del teléfono y un público inmutable de adoquines y de columnas de fierro" (pp. 38-39). En este sentido, así como Aira y Amícola reconocen rasgos expresionistas en la obra de Roberto Arlt, también es posible advertir estas características en las ficciones de su amigo Castelnuovo, publicadas algunos años antes. El narrador de "Tinieblas", al día siguiente, pasa junto a la mujer una vez más, evoca a Cristo como modelo para su acción y, por "lástima” (p. 40), decide llevarla a su barraca "fea, despintada, pero limpia" (p. 37) para darle resguardo. Con el correr de los días la condición física de la joven mejora y comienza a crecer una relación afectiva entre ellos, pese a los sentimientos contradictorios del narrador respecto de su aspecto físico. Luisa no sólo era “raquítica” (p. 40) sino que también tenía una joroba, motivo por el que el protagonista, desde su perspectiva lombrosiana, siente rechazo por la descendencia que ella podría llegar a engendrar: "niños desnutridos, estúpidos, idiotas" (p. 45). Durante su convivencia, no obstante, se genera un deseo sexual entre ellos, que crece a tal punto que el narrador señala que Luisa "parecía una santa enclaustrada a quien el demonio rompiese las cadenas que oprimían su oscura virginidad” (p. 
47). Finalmente, antes de "poseerla" (p. 47), el narrador se dice a sí mismo "Cristo me abandonó... Nos abandonó...” (p. 47), donde expone la culpa que le genera la contradicción entre su deseo y su moral religiosa. Al día siguiente, no obstante, se pone en evidencia su hipocresía cuando descarga la responsabilidad del "pecado" (p. 49) únicamente sobre Luisa:

-Hemos pecado...

${ }_{-¿ \text { Hemos pecado? }}$

-Sí... nos hemos condenado para siempre.

En las negruras del sueño mis ideas religiosas aparecen en toda su terrible austeridad.

-Vos tenés la culpa... Yo no quise: Cristo fue testigo de que yo no quise... (p. 49)

De esta manera, como efecto de lectura, se produce una vez más un distanciamiento crítico respecto de la doble moral del narrador, impugnación de su figura que se profundiza en vistas del desprecio con que reacciona cuando Luisa le comunica que está embarazada: “¡Ah, Cristo, Cristo!... ¿ por qué me abandonaste? ¿por qué? ¿por qué?” (p. 51). Con el transcurso del embarazo, Luisa padece un decaimiento físico extremo y el narrador percibe que "cuando camina se dobla como si llevara un castigo de piedra en el abdomen" (p. 51). Una noche el protagonista llega a su casa y encuentra a Luisa que "agonizaba en un charco de sangre” (p. 52):

Levanté las sábanas y descubrí un fenómeno macabro. La cabeza semejaba por sus planos un perro extraño y era tan chata que se sumergía hasta hacerse imperceptible en el cráter de una joroba quebrada en tres puntos. Su cuerpo estaba revestido de pelos largos; no tenía brazos y las piernas eran dos muñones horrorosos. Volví a cubrirlo, me senté aniquilado en una silla y así me sorprendió el día siguiente. El nene bajo las sábanas se revolvía como un gusano y lanzaba unos vagidos que me helaban el corazón (p. 53).

Por último, Luisa murió "sin pronunciar una queja” y el recién nacido "se ahogó en un lago de sangre" (p. 53). La situación final presenta al narrador pasando sus días sin poder dormir, yendo "de aquí para allí como un loco" y, nuevamente, "atormentado y perseguido por una voz" que le repetía: “¿Qué has hecho, hijo mío?” (p. 53). Este final, de manera extrema, traiciona toda expectativa de felicidad y, por el contrario, en él los personajes encuentran la muerte o permanecen, como el protagonista, sumidos en la tristeza. Este desenlace hiperbólicamente trágico es uno de los pasajes más utilizados por la crítica literaria para ejemplificar los rasgos naturalistas, biologicistas, tremendistas y de "mal gusto" de la poética de Castelnuovo, que entrarían en contradicción con el proyecto político-cultural de Boedo. No obstante, es posible reconocer en este final, no una afirmación de esas características sino una serie de exageraciones e inversiones paródicas y burlescas sobre la literatura dominante de la época. En este sentido, por un lado, Castelnuovo invierte con ironía los finales felices de la narrativa sentimental, de gran éxito de público en la época. Estas ficciones se distinguen, como afirma Beatriz Sarlo (2000), por constituirse en "textos de la felicidad" que se apoyan sobre dos convicciones: la certeza de que la felicidad se encuentra al "alcance de la mano [...], anclada en el [...] matrimonio y la familia" (p. 22) y, asimismo, la creencia en que "el mundo no debe necesariamente ser cambiado para que los hombres y las mujeres sean felices" (p. 22). En efecto, el narrador de "Notas de un literato naturalista" afirma sobre Gustavo Martínez Zuviría, escritor católico que, bajo el pseudónimo de Hugo Wast, fue uno de los principales autores de la narrativa sentimental durante esos años: "es el mariscal de esta partida de garibaldino que están envenenando al pueblo con los gases asfixiantes de sus blandicies espirituales” (1923a, p. 2). Esas palabras del narrador son convergentes con la valoración que Castelnuovo realiza en sus Memorias (1974) de la novela semanal, a la que se refiere como una "plaga literaria" (p. 125), una "verdadera peste" (p. 125) que "suministraba [...] opio a la ciudadanía" (p. 125). De esta manera, el trágico final de este relato pone en acto la demolición de cualquier expectativa de felicidad en el marco de la familia y el matrimonio, así como expone el sinsentido de las esperanzas que el protagonista deposita en Dios. Asimismo, este desenlace destruye con sarcasmo el pietismo y el mesianismo que motivaron al narrador a "rescatar" a Luisa de la pobreza y la exclusión social. El sarcasmo para la crítica del imaginario católico tiene precedentes en las producciones de Castelnuovo en tanto, por ejemplo, "Catecismo", breve diálogo ficcional entre un sacerdote y un obrero - 
publicado en el tercer número de la revista Prometeo, de septiembre de 1919- ridiculiza con humor la relación opresiva e interesada que se establece entre ambos personajes. ${ }^{5}$

Por su parte, la descripción del niño recién nacido sorprende por el énfasis en los detalles de su monstruosidad, cuya dimensión paródica se advierte cuando se reconoce en su configuración la presencia como sustrato de un pasaje de Sin rumbo (1885), del escritor naturalista Eugenio Cambaceres. En un momento de la trama, Andrés, joven terrateniente protagonista de la novela, fantasea sobre su futuro, dado que una de las empleadas de su estancia, con quien mantenía relaciones sexuales ocasionales, estaba embarazada de él:

envuelta en las caprichosas redes de la fantasía y de la vaga y opaca nebulosa provocada por el sueño de Andrés, repentinamente un monstruo se desprendía.

Un monstruo horrible, un enano deforme, de piernas flacas y arqueadas, de cabeza desmedida, de frente idiota.

Los músculos tirantes, inyectadas las venas del pescuezo, como al extremo de reventar bajo la piel amoratada y fofa, en el enorme esfuerzo, un sonido inarticulado atinaba sólo a salir de su garganta, estridente, agrio, semejante al grito avieso de la lechuza (Cambaceres, 1992 [1885], p. 64).

La descripción hiperbólica de Castelnuovo de la escena del parto y de la monstruosidad del recién nacido se articula a partir de hacer realidad las fantasías de Andrés en Sin rumbo y, así, al poner en evidencia su inverosimilitud, se ridiculiza el determinismo biológico que funciona de sustento ideológico del conjunto de las obras de Cambaceres y del naturalismo argentino en general. Algunos años después, Castelnuovo hace explícita esta crítica al naturalismo y su cientificismo determinista en su "Prólogo" a Vidas proletarias (1934), compilación de obras de teatro de su autoría:

La concepción científica de Emilio Zola, principal animador del naturalismo francés, [...] no iba nunca más allá de la patología. Todo su naturalismo, como se recordará, giraba lamentablemente en torno a las taras hereditarias, al flujo y reflujo de las propensiones mórbidas, al extremo de que sus héroes actuaban, por lo regular, a través de un microbio intransigente que le había transmitido algún antepasado y que terminaba a la postre por liquidar a toda la familia. El complejo problema social quedaba reducido de este modo a un mero problema hospitalario. Se observaba, entonces, al individuo separadamente de la sociedad y a la sociedad separadamente de sus antagonismos de clase (p. 14).

De esta manera, el cuento "Tinieblas" se estructura a partir de la inversión y de la exageración paródica de la narrativa sentimental de matriz católica y del naturalismo lombrosiano de Eugenio Cambaceres, dos de las tendencias literarias dominantes de su contexto de producción, con el objetivo de criticar tanto sus opciones poéticas como los presupuestos ideológicos que sostienen, al tiempo que Castelnuovo apela a una sensibilidad expresionista para dar forma literaria a la denuncia de las consecuencias sociales del capitalismo.

\section{“De Profundis": PARodia y homenaje a la literatura de Horacio Quiroga}

En "De profundis", segundo relato de la primera edición de Tinieblas -y tercero en las siguientes- se despliega una serie de referencias paródicas a la literatura de Horacio Quiroga, las que, al mismo tiempo, funcionan como un homenaje a su obra. Esta misma ambivalencia respecto de la figura de Quiroga también se percibe en el capítulo que le dedica Castelnuovo en sus Memorias. Allí señala que lo conoce en 1924, "ya en el apogeo de su reputación literaria” (1974, p. 174) y afirma con ironía que:

Antes de entregarse [Quiroga] a la forestación en la selva de Misiones, vivía negligentemente en Montevideo, rentado por la madre, ajeno a toda preocupación económica, divorciado de la actividad real y de la realidad que lo circundaba, y arando intelectualmente en la superficie de los acontecimientos (1974, p. 177).

Junto con estas críticas, no obstante, Castelnuovo le reconoce a Quiroga -a quien califica como "niño mimado de la madre" (1974, p. 180)- ${ }^{6}$ el hecho de que fue "el único [escritor] de su generación que superó 
el romanticismo y la verbosidad de su época. Él único que redujo en su escritura la ornamentación barroca, entonces en boga, a su más escueta estructuración gramatical” (p. 180).

En efecto, la caracterización del narrador de "De profundis" muestra correspondencias con la descripción de Quiroga que realiza Castelnuovo en sus Memorias, dado que, en las frases iniciales del cuento, se hace énfasis en el apego del protagonista hacia su madre y en su deriva por la selva luego de partir desde Uruguay:

Cuando salí de Montevideo en un estado de sonambulismo que me duró cerca de tres años, creo que atravesé el Uruguay a pie y me interné en el Brasil por Santa Ana. [...] [L]a muerte de mi madre extinguió en parte la luz que alumbraba mi cerebro y yo empecé a rodar por el mundo como un borracho a través de las tinieblas (1923b, p. 56).

Santa Ana, en efecto, es uno de los pueblos cercanos a las tierras que compra Quiroga en 1906 y en donde reside con intermitencias durante su primera experiencia en Misiones.

Sin embargo, estas referencias a Quiroga se entraman en la configuración del personaje del narrador con un imaginario católico que, una vez más, se critica en este cuento de manera similar a como ocurría en “Tinieblas". En este sentido, todo el relato se desarrolla a partir del monólogo del narrador frente a la tumba de Irene, el amor de su infancia, a quien visita cuando retorna a Montevideo, donde descubre que murió en su ausencia de tuberculosis. En ese marco, el narrador le cuenta que, luego de enterarse de la muerte de su madre, camina "maquinalmente" repitiéndose a cada momento "mi madre ha muerto" (1923b, p. 58) y sintiendo que "una maldición sagrada” hubiese caído sobre sus espaldas (p. 58). Asimismo, también relata siempre frente al sepulcro de Irene- que no se llama más "Alfredo" sino que se llama "guacho", sobrenombre que le puso el capataz de "La Charqueada", "un negro espantoso, trompudo, picado de viruelas" (p. 58) que lo somete a distintos tipos de maltratos. Dada las deplorables condiciones de trabajo, el narrador enferma y lo despiden, no sin que antes este capataz le deje "en el cuerpo la cicatriz de varios rebencazos, el sello de la brutalidad humana" (p. 58): si en "Tinieblas" se denuncian las cruentas condiciones del trabajo urbano, en "De profundis" se expone el oscuro escenario de la explotación rural.

Como consecuencia de su enfermedad y de los maltratos padecidos, el narrador abandona "La Charqueada" acompañado de "dos sombras" (1923b, p. 60) que siguieron sus pasos y que lo "guiaban a través de las tinieblas" (p. 60), la de su madre y la de Irene. No obstante, la sombra de su madre "desapareció" al poco tiempo y, bajo una fuerte tormenta, parte con la sombra de Irene "a sus espaldas" (p. 60) a recorrer "la inmensidad de las selvas vírgenes y desoladas” (p.60). En este giro fantástico del relato, inusual en la narrativa de Castelnuovo, se puede reconocer otra referencia a la literatura de Quiroga. Como consecuencia del miedo que padece en esa situación, el narrador se pone a "rezar" (p. 67) y siente "una masa peluda" (p. 67) sobre sus espaldas y "cinco garras agudas" (p. 67) que le comprimían el cráneo: "Debe ser una serpiente -penséuna culebra enorme que quiere enroscarse a mi cuerpo para devorarme” (p. 67). A pesar de este pensamiento que anticipa el final, descubre que en verdad se encontraba enfrente de "un mono de unos 80 centímetros de altura, compungido y lloroso" (p. 68). Luego de que dialogan con señas, el narrador descubre que la tormenta que azotaba la selva había tirado de un árbol al animal, que se había lastimado un brazo. El protagonista decide ayudarlo porque tiene "un corazón tiernísimo" (p. 68) y le hace un vendaje en el brazo con una tira de sus ropas: "Aquí sucedió algo curioso: el mono profundamente agradecido me abrazó con verdadera efusión y desapareció luego entre las nieblas espesas de los pajonales” (p. 69). En las exageraciones de esta escena que aproximan las acciones al terreno del absurdo, se percibe la recreación con tono paródico de las ayudas y agradecimientos recíprocos entre personajes humanos y animales, propios de los relatos de Cuentos de la selva (1917), de Horacio Quiroga.

Luego de curar al mono, el narrador percibe a lo lejos "un bulto informe, fantástico" (1923b, p. 69) que se aproxima, que resulta ser una carreta, cuyo conductor le permite subir a bordo. Una vez sobre el vehículo, busca refugio debajo de su poncho. Ante este gesto, el conductor le pregunta: “-¿Sos oriental? [...] -Te digo esto porque todos los orientales son confianzudos y sinvergüenzas: yo soy oriental” (p. 71). En este encuentro de dos uruguayos en el relato se puede advertir una puesta en abismo humorística del 
cruce paródico - “confianzudo y sinvergüenza”- que formula Castelnuovo sobre la literatura de Quiroga en la factura de su ficción. En este sentido, Michel Foucault señala que uno de los rasgos fundamentales de la literatura moderna consiste en su capacidad de ofrecer su propia “autorreferencia” (1996, p. 88), es decir, una "implicación que la obra se hace a sí misma” (1996, p. 89) como forma de dar indicios sobre sus estrategias de sentido.

Luego, el narrador baja de la carreta frente al lugar donde buscaría una nueva oportunidad de trabajo, se encuentra con el mono - quien está acompañado también de una mona- y se abrazan una vez más. Consigue trabajo en la cantera y le ofrecen significativamente como vivienda

$\mathrm{n}$ rancho de lozas en el cual había un colchón de plumas sobre dos tirantes, una olla de comida en el suelo y varios cubiertos de lata. (...) -Isto colchao de pluma o deixou outro rapaz que moraba qui, porque ele diz que hay diabos adintro... Vocé o pode aproveitar...

un rancho de lozas en el cual había un colchón de plumas sobre dos tirantes, una olla de comida en el suelo y varios cubiertos de lata. (...) -Isto colchao de pluma o deixou outro rapaz que moraba qui, porque ele diz que hay diabos adintro... Vocé o pode aproveitar...

-¿Diablos adentro del colchón? -exclamé- ¿Cómo es eso? (p. 75)

La referencia paródica a Quiroga se hace aún más transparente: el “almohadón de plumas” -título del relato publicado en Cuentos de amor de locura y de muerte (1917) - crece exageradamente y se convierte en un "colchón”, el que, así como ocurre en el cuento de Quiroga, es una pieza fundamental para comprender la enfermedad posterior del protagonista. En el rancho, el narrador conforma una "familia" (1923b, p. 79) con los dos monos, un ratón y una serpiente, que los primates reciben con desconfianza. Asimismo, el narrador señala -en un deseo, en principio, disparatado- que le "hubiese gustado" (p. 79) contar con la compañía de "una gaviota a fin de poder acariciarla y contarle una por una, todas sus plumas blancas y bruñidas como la playa..." (p. 79). Este anhelo del protagonista revela su sentido cuando se advierte una nueva referencia a Quiroga: la chalana con la que recorre el río Paraná este escritor se llama, precisamente, "La gaviota” y había sido bautizada con ese nombre durante "una ceremonia que es muy comentada por las crónicas socialliterarias" de la época (Lafforgue, 1996, p. 1243). En un nuevo giro humorístico, asimismo, el narrador señala que los monos "ciertas cosas las aprendían con suma facilidad, como por ejemplo, espumar la olla, barrer el piso, cazar moscas” (pp. 79-80) y se ofrece, así, una burla a la humanización de los animales de muchos de los relatos de Quiroga.

Los problemas del narrador con la serpiente se convierten, a partir de allí, en el conflicto narrativo principal y comienzan cuando este le pide al animal que deje de silbar de noche porque molesta durante el descanso. Como respuesta, la serpiente "se mostró en lo sucesivo más hosca que de ordinario" (1923b, p. 81). En este contexto, el narrador percibe que su "salud decaía" (p. 84) y que se "ponía cada vez más flaco" (p. 84), pese a que "no acertaba a definir" (p. 84) qué le ocurría: “-¿Qué me pasa, Dios mío, qué me pasa? [...] Ahora, cuando me acostaba sobre el colchón de plumas, dada mi delgadez, me hundía completamente, desaparecía...” (p. 84). El protagonista, como frente a cada situación conflictiva de su vida, atribuye la causa de sus padecimientos al hecho de no haber cumplido una promesa religiosa hecha por su madre cuando él era niño, para que se curara de unas quemaduras: "Dios me maldijo - pensaba- y me condenó a marchar perpetuamente por el estercolero terrestre. Por rebelde, sí, por rebelde, por no querer llevar siempre el hábito de carmelita, me arrancó padre y madre y me condenó a la soledad y al trabajo" (pp. 84-85). El narrador encuentra en su "rebeldía" la causa del castigo divino y se destaca con sarcasmo, como consecuencia, la conformación de subjetividades resignadas y obedientes por parte de la religión. Estos razonamientos del protagonista mueven a la risa por su rigidez esquemática, al modo en que Henri Bergson señala que lo cómico en el arte acontece cuando pone en evidencia aquellos aspectos de las personas y la sociedad que, por su automatismo, las hace asemejarse a una cosa (2009, p. 68). En este sentido, los esquematismos y conductas automáticas e irreflexivas de los personajes de Castelnuovo buscan, a través de la distancia crítica de la risa, poner en cuestión el tipo de subjetividad que produce la cultura dominante, con la moral religiosa y la literatura sentimental como dos de 
sus exponentes más relevantes. Con el desarrollo del relato, los problemas físicos del narrador se acrecientan: siente que se iba "extinguiendo como una planta sin riego puesta en la oscuridad" (p. 85) al tiempo que sueña "que las plumas, en cuanto apagaba la luz, abandonaban el colchón subrepticiamente" (p. 85) y le "chupaban la sangre" (p. 85):

A veces, despertaba sobresaltado, oscurecido, ciego, como si una trompa de absorción me hubiese cogido una arteria y tirase pertinazmente con el propósito de vaciarla.

En seguida, oía algo que se desprendía del techo y se arrastraba precipitadamente por la tierra como una babosa gigantesca y derrengada (1923b, p. 85).

Su desconfianza respecto del colchón aumenta y percibe que dentro de él "pululaba un hormiguero, un monstruo tentacular se agitaba, había algo horrible y dantesco que ondulaba eléctricamente como una culebra" (p. 86):

-No estoy loco, no -confesaba. -Pero las plumas, ¿saben? ¡las plumas me van a dejar sin sangre!

Luego me asaltaba una duda: ¿tienen vida propia las plumas? ¿Tienen una trompa simulada que no distingo y con la cual me despojan la sangre? ¿O serán diablos, aquellos diablos de quienes me habló aquel hombre cuando yo llegué? (1923b, p. 86)

Finalmente, el narrador decide develar el misterio y una noche se pone "en guardia" (p. 88) porque quería "descubrir si en realidad eran las plumas" quienes le "chupaban la sangre” (p. 88). Menos de una hora después, siente "un bulto largo" (p. 88) que recorría sus piernas y que "junto al muslo izquierdo se detuvo" (p. 89) y le aplicó "algo así como una ventosa cortada, pero absorbente, finísima y agradable" (p. 89). El narrador imagina que es "una pluma monstruosa dotada de una trompa de sanguijuela" (p. 89) que le "extraía la poca sangre" (p. 89) que le restaba. Estos pasajes, en efecto, se constituyen a partir de la exageración de las descripciones del parásito que succiona noche a noche la sangre de Alicia hasta matarla, protagonista del cuento de Quiroga "El almohadón de plumas": "sobre el fondo [del almohadón], entre las plumas, moviendo lentamente las patas velludas, había un animal monstruoso, una bola viviente y viscosa” (Quiroga, 1996 [1917], p. 101) que aplicaba "sigilosamente su boca -su trompa, mejor dicho-a las sienes [de Alicia] (...) chupándole la sangre" (p. 101). En este sentido, el narrador de "De profundis" señala que "a pesar del olor fuerte a fiebre, a suciedad y a cadáver en descomposición que reinaba bajo la manta” (p. 89) aventuró allí su cabeza y pudo "distinguir clara y distintamente el compás de una trompa ebria que succionaba" (p. 89): "Estiré la mano para atraparla y tropecé con una masa blanda, gelatinosa, horrible... Era la serpiente, mi hermana, mi terrible hermana: ¡la serpiente!..." (p. 89). En esta rivalidad entre la serpiente y el protagonista puede advertirse, asimismo, una nueva referencia a Quiroga por su similitud con los conflictos principales de Anaconda (1921), que giran en torno al enfrentamiento en la selva entre serpientes y humanos. Ante esta situación, esa noche siente que llega al rancho nuevamente la sombra de Irene y lo "salva", porque después de su visita espectral, decide ir a su encuentro en Montevideo, luego de tres años de ausencia. Allí, busca a Irene en su casa, le informan de su muerte y decide ir al cementerio a postrarse "de rodillas sobre el fango helado" (p. 92) de su sepulcro, para pedirle que lo perdone: "Por mis culpas, por mis gravísimas culpas, por todos mis pecados, perdoname... ¡Ah, por rebelde, sí, por rebelde, Dios que es tan bueno, me castiga así!...” (p. 92). En el final, el narrador se pone "de pie delirante" (p. 92) y clama "como nunca" (p. 92): “-Dios generoso... ¡Santo, santo, santo!... ¡Suéltame un rayo! ¡Suéltale un rayo a ele, a ele! ¡Pega, pega que e guacho!” (p. 92). Estas órdenes en portugués -que son las últimas palabras del cuento- son las mismas que su capataz de "La Charqueada" - "trompudo" como el parásito y la serpiente - profería al momento de castigarlo para que realice con mayor intensidad su trabajo. De esta manera, en la introyección y reproducción del discurso de su agresor se denuncia con ironía la convergencia entre la culpa religiosa, la necesidad del narrador de castigo por sus "rebeldías" y las relaciones sociales de explotación capitalista. Asimismo, los elementos fantásticos del relato, su ambiente selvático y las exageraciones y giros paródicos sobre los modelos de los relatos de Quiroga ofrecen una crítica humorística del divorcio de su literatura "de la actividad real y de la realidad que lo circundaba" (p. 177), como afirma 
Castelnuovo en sus Memorias (1974) al tiempo que, en el mismo gesto, se realiza -como la otra cara de estos recursos paródicos- un reconocimiento de las innovaciones literarias de Quiroga.

\section{El humor de CAstelnuovo en Tinieblas: tono Clave PARA UNA RELECTURA De SU OBRA}

Las inversiones, burlas y parodias que Castelnuovo articula respecto del naturalismo, la novela sentimental y la narrativa de Horacio Quiroga ofrecen una forma de destrucción de las tendencias literarias dominantes de su época, en concordancia con los objetivos de su proyecto literario, que hace explícito en su "Prólogo" a Vidas proletarias (1934):

La literatura proletaria rusa es una literatura constructiva, en virtud de que atraviesa la etapa de la construcción del socialismo. La nuestra, en cambio, es o debe ser destructiva, en razón de que cruza la recta de la destrucción del capital. Toda la literatura rusa, ahora, está absorbida por un solo pensamiento: construcción. La nuestra no puede ser absorbida más que por la idea contraria: destrucción (p. 19).

Dentro de este marco, advertir el humor de la literatura de Castelnuovo, presente desde sus primeras publicaciones, permite comprender las continuidades entre su proyecto político-cultural y sus obras literarias. En este sentido, Castelnuovo no reivindica el "pietismo religioso" ni el "fatidismo mesiánico", sino que exagera estos tópicos con el fin de satirizar el imaginario católico, de gran presencia dentro de la literatura de su contexto. De esta manera, expone que la "conmiseración con los pobres" de raigambre cristiana, lejos de resolver los problemas de los personajes, los agrava, al punto que los desenlaces de sus cuentos son extremadamente trágicos. Un gesto similar realiza Castelnuovo, asimismo, respecto del naturalismo literario, en tanto el supuesto "voyeurismo" e "ingenuo tremendismo" de su literatura, son formas de la exageración paródica y burlesca de esa tendencia literaria, con el fin de impugnar el determinismo biológico que sostiene como tesis. En contraposición, la apuesta de Castelnuovo por el uso de una sensibilidad expresionista enfatiza la distancia estética que busca establecer con la literatura que critica en su obra y de aproximarse a las formas novedosas de las vanguardias históricas europeas.

Por su parte, en relación con Horacio Quiroga, los procedimientos paródicos muestran una doble finalidad: por un lado, son utilizados con el objetivo de cuestionar la desvinculación que encuentra Castelnuovo entre su literatura y las problemáticas sociales, mientras que, por otro, reconocen la renovación literaria que provocó Quiroga y la búsqueda de otras formas de expresión literarias, alternativas a la “ornamentación barroca”, por ejemplo, del romanticismo de Vargas Vila, que Castelnuovo cuestiona explícitamente en su obra periodística. ${ }^{7}$

Si bien existen algunos desarrollos críticos que reconocen la condición de humorista y parodista de Castelnuovo, señalan que es una excepcionalidad que acontece en el comienzo de su producción y que ya en Tinieblas abandona por el tono serio para la denuncia social. No obstante, el tono humorístico y paródico se articula como un rasgo constitutivo fundamental de estos relatos de Tinieblas, con el objetivo de destruir a las tendencias literarias dominantes de su época, y a las ideologías que sustentan, a través de la risa. El humor tragicómico de la narrativa de Castelnuovo, así como su sensibilidad expresionista, entrama la clave de la coherencia entre su literatura y el proyecto político y cultural emancipatorio del que participa.

\section{ReFERENCIAS}

Aira, C. (1993). Arlt. Paradoxa, 7, 55-71.

Amícola, J. (2008). Fritz Lang, Alfred Döblin y Roberto Arlt. En W. Nitsch, M. Chihaia y A. Torres (Eds.), Ficciones de los medios en la periferia. Técnicas de comunicación en la literatura hispanoamericana moderna (pp. 161-169). Köln: Universitäts und Stadtbibliothek Köln, (Kölner elektronische Schriftenreihe, 1). 
Astutti, A. (2002). Elías Castelnuovo o las intenciones didácticas de la narrativa de Boedo. En M. T. Gramuglio (Dir.) y J. Noé (Ed.) El imperio realista. Historia Critica de la Literatura Argentina (vol.6, pp. 417-446). Buenos Aires: Emecé.

Bergson, H. (2009). La risa. Ensayo sobre el significado de lo cómico. Buenos Aires: Losada.

Blanco, O. (2012). Modulaciones de un realismo (/naturalismo) militante. Direcciones invertidas: del naturalismo argentino a la literatura de Boedo. En M. Vitagliano (Comp.), Boedo. Politicas del realismo (pp. 15-52). Buenos Aires: Título.

Cambaceres, E. (1992 [1885]). Sin Rumbo. Buenos Aires: CEAL.

Candiano, L. y Peralta L. (2007). Boedo: Orígenes de una literatura militante. Historia del primer movimiento cultural de izquierda argentina. Buenos Aires: Ediciones del CCC.

Castelnuovo, E. (1919). Catecismo. Prometeo, 1(3), 4.

Castelnuovo, E. (1923). La era vargasviliana de Vargas Vila. El libertario, 6 (s/p).

Castelnuovo, E. (1923a). Notas de un literato naturalista. Buenos Aires: Las Grandes Obras.

Castelnuovo, E. (1923b). Tinieblas. Buenos Aires: Tognolini.

Castelnuovo, E. (1934). Vidas proletarias. Buenos Aires: Victoria.

Castelnuovo, E. (1974). Memorias. Buenos Aires: Ediciones culturales argentinas.

Croce, M. (2017). Novelistas y cronistas de la monstruosidad: avatares del grotesco en el primer cuarto del siglo xx. En M. Croce (Comp.), Historia comparada de las literaturas argentina y brasileña: de la crisis bursátil al nacionalismo católico: 1890-1922 (pp. 184-240). Villa María: Eduvim.

Eipper, J. E. (1995). Elías Castelnuovo. La revolución hecha palabra. Buenos Aires: Rescate.

Eujenián, A. y Giordano A. (2002). Las revistas de izquierda y la función de la literatura: enseñanza y propaganda. En M. T. Gramuglio (Dir.) El imperio realista (vol. 6), J. Noé (Ed.) Historia Crítica de la Literatura Argentina (pp. 395-416). Buenos Aires: Emecé.

Foucault, M. (1996). De Lenguaje y literatura. Barcelona, España: Paidós.

García Cedro, G. (2013). Ajuste de cuentas. Boedo y Florida entre la vanguardia y el mercado. Buenos Aires: Santiago Arcos.

Giordano, C. (1980 [1968]). Boedo y el tema social. En S. Zanetti (Ed.), Los proyectos de la vanguardia. Capitulo. Historia de la literatura argentina (vol. 4, pp. 25-48). Buenos Aires: CEAL.

Lafforgue, J. (1996). Cronología. En H. Quiroga, Todos los cuentos (pp. 1233-1254). Nanterre: Colección Archivos, Fondo de Cultura Económica.

Larra, R. (1978). Roberto Arlt, el torturado: una apasionada biografía. Buenos Aires: Ameghino Editora.

Larra, R. (1998). Leónidas Barletta. Buenos Aires: Ediciones Conducta.

Masiello, F. (1986). Lenguaje e ideologia: las escuelas argentinas de vanguardia. Buenos Aires: Hachette.

Montaldo, G. (2006 [1989]). Literatura de izquierda: humanitarismo y pedagogía. En G. Montaldo (Dir.), Yrigoyen entre Borges y Arlt (1916-1930) (pp. 324-344). Buenos Aires: Paradiso.

Montaldo, G. (1990). Los Pensadores y Claridad: una propuesta cultural de la izquierda argentina (1922-1941). América: Cahiers du CRICCAL, Le discours culturel dans les revues latino-américaines de l'entre-deux guerres, 1919-1939, 4-5, 421-430. https://www.doi.org/10.3406/ameri.1990.1002

Monteagudo, A. (2012). El teatro de las tinieblas. En M. Vitagliano (Comp.), Boedo. Políticas del realismo (pp. 117-132). Buenos Aires: Título.

Portantiero, J. C. (1961). Realismo y realidad en la narrativa argentina. Buenos Aires: Procyón.

Prieto, A. (1959). La literatura de izquierda. El grupo de Boedo. Fichero, 2, 17-20).

Prieto, A. (1964). Prólogo. En A. Prieto (Comp.), Antología de Boedo y Florida (pp. 7-12). Córdoba: Universidad Nacional de Córdoba.

Prieto, M. (2011 [2006]). Breve historia de la literatura argentina. Buenos Aires: Taurus. 
Quiroga, H. (1996 [1917]). Cuentos de amor de locura y de muerte. En Todos los cuentos. Nanterre: Fondo de Cultura Económica, Colección Archivos.

Redacción (1925). Propósitos de la biblioteca Los Nuevos. Los pensadores, 6 (ó 106), Año III (s/p).

Rodríguez Pérsico, A. (2012). Elías Castelnuovo: saberes linyeras y estética del desecho. Zama, 4(4), 89-98.

Rodríguez Pérsico, A. (2013). Capitalismo y exclusión. Elías Castelnuovo y la búsqueda de una lengua heterogénea, Estudio preliminar. En E. Castelnuovo, Larvas (pp. 9-84). Buenos Aires: Biblioteca Nacional.

Rodríguez Pérsico, A. (2014a). Elías Castelnuovo: una lectura plebeya del freudismo. Outra Travessia, 17, 51-70. htt p://dx.doi.org/10.5007/2176-8552.2014n17p51

Rodríguez Pérsico, A. (2014b). Literaturas heterogéneas. El malentendido de Elías Castelnuovo. El taco en la brea, 1(1), 288-300. https://doi.org/10.14409/tb.v1i1.4205

Romano, E. (1981). El cuento. 1900-1930. En S. Zanetti (Ed.), Las primeras décadas del siglo (vol.3), Capitulo. Historia de la literatura argentina (pp. 457-480). Buenos Aires: CEAL.

Rosa, N. (1997). La lengua del ausente. Buenos Aires: Biblos.

Saítta, S. (2008). Elías Castelnuovo, entre el espanto y la ternura. En Á. F. Bolaños, G. Cleary Nichols y S. Sosnowski (Eds.) Literatura, politica y sociedad: construcciones de sentido en la Hispanoamérica contemporánea. Homenaje a Andrés Avellaneda (pp. 99-113). Pittsburg, Estados Unidos: Instituto Internacional de Literatura Iberoamericana, Universidad de Pittsburg.

Sarlo, B. (1988). Una modernidad periférica: Buenos Aires 1920-1930. Buenos Aires: Nueva Visión.

Sarlo, B. (2000 [1985]). El imperio de los sentimientos. Narraciones de circulación periódica en la Argentina (1917-1927). Buenos Aires: Norma.

Vitagliano, M. (2012). El escritor de la época afónica. En M. Vitagliano (Comp.), Boedo. Políticas del realismo (pp. 77-95). Buenos Aires: Título.

Zas, L. (1988). Nacimiento, vida, muerte y resurrección del Grupo de Boedo. Buenos Aires: Rescate.

\section{Notas}

1 En este sentido, trabajos que forman parte de esta tendencia se publicaron, por ejemplo, en Historia de la literatura argentina, del Centro Editor de América Latina (con una primera edición en 1967, ampliada en la reedición de 1979) y, más recientemente, en las colecciones de historia de la literatura argentina dirigidas por David Viñas (volumen 3, compilado por Graciela Montaldo, en 1989) y por Noé Jitrik (volumen 6, compilado por María Teresa Gramuglio, en 2002).

2 Croce (2017) también señala el gesto paródico de Castelnuovo hacia el naturalismo, pero, pese a haber caracterizado al autor como un "extremista del morbo", no saca conclusiones al respecto: "Castelnuovo no vacila ante la parodia cuando acude a los temas naturalistas y los filtra desde una aproximación expresionista” (pp. 203-204).

3 Todas las citas de Tinieblas (1923b) se realizan a partir de esta primera edición.

4 De aquí en más, todas las citas de Tinieblas se realizan a partir de esta edición.

5 En "Catecismo", por ejemplo, se hacen referencias sarcásticas a la relación entre la Iglesia Católica y la cruenta represión operada sobre los trabajadores - cuyos núcleos más activos se encontraban dentro del anarquismo- en la llamada Semana Trágica, ocurrida en enero de 1919 durante el gobierno de Hipólito Yrigoyen, pocos meses antes de la publicación del texto:

"S[acerdote].- ¿Crees en la abnegación de la liga patriótica que se propone castrar todos los cerebros y concluir a balazos las huelgas que fomentan los agitadores de oficio?

O[brero].- Sí, padre.

S. - ¿Te falta algo por creer?

O.- Creo que no.

S. - ¿Crees que crees?

O.- Creo.

S.- (Le da una hostia bendita que el paciente traga con voracidad)" (1919, p. 4). 
El diálogo entre ambos personajes interrumpe su tono cortés - pero no su efecto humorístico- cuando el obrero le manifiesta al sacerdote que tiene hambre. Ante las evasivas del sacerdote, el malestar del obrero crece en intensidad y el diálogo finaliza con una situación de violencia cercana al gag y con unas palabras del sacerdote cargadas de ironía: S.- ...¿Crees que nuestro señor Jesucristo...

O.- ¿ ¡ Jesucristo es un idiota!

S.- ¡A Ah! (Lo toma del pelo y le empieza a dar botinazos) ¡No digas eso de Jesucristo! ¡No digas eso de Jesucristo... me cago en Dios! (p. 4).

6 Jorge Lafforgue describe a Quiroga en su infancia, al igual que Castelnuovo, como "un niño retraído, nervioso, asmático, protegido por su madre" (1996, p. 1233).

7 Por ejemplo, ver "La era vargasviliana de Vargas Vila", en el número 6 de El libertario, del 20 de mayo de 1919. 